\title{
The investigation of sediment processes in rivers by means of the Acoustic Doppler Profiler
}

\author{
M. GUERRERO \\ Hydraulic Engineering Laboratory-DICAM, University of Bologna, Italy \\ massimo.guerrero@unibo.it
}

\begin{abstract}
The measurement of sediment processes at the scale of a river cross-section is desirable for the evaluation of many issues related to river hydro-morphodynamics, such as the calibration and validation of numerical models for predicting the climate change impacts on water resources and efforts of maintenance of the navigation channel and other hydraulic works. Suspended- and bed-load have traditionally been measured by cumbersome techniques that are difficult to apply in large rivers. The acoustics for the investigation of small-scale sedimentological processes gained acceptance in the marine community because of its ability to simultaneously profile sediment concentration and size distribution, non-intrusively, and with high temporal and spatial resolution. The application of these methods in true riverine case studies presents additional difficulties, mainly related to water depths and stream currents that limit sound propagation into water and challenge the instruments deployment, especially during floods. This article introduces the motivations for using the ADCP for sediment processes investigation other than for flow discharge measurement, summarizes the developed methods and indicates future desirable improvements. In addition, an application on the Po River in Italy is presented, focusing on the calibration of the existing software by means of ADCP recordings. The calibrated model will assist in planning the dredging activities to maintain the navigation channel and the intake of a pump station for irrigation that is periodically obstructed with a sandbar.
\end{abstract}

Key words sediment transport, rivers, Acoustic Doppler Current Profiler

\section{INTRODUCTION}

The development of Acoustic Doppler Current Profiler (ADCP) methods capable of estimating significant physical processes has a great potential for the understanding of sediment transport and morphodynamics in sandy rivers. In particular, the ADCP was successfully applied in fixed or moving deployments to map flow velocities, suspended sediment and near bed processes (i.e. friction and bed load). Therefore, the estimation of these parameters may conveniently be divided into three classes for fluvial processes investigation: (i) the hydrodynamics, (ii) the sediment field, and (iii) the bedforms dynamics. These classes have reciprocal feedbacks that challenge the complete understanding of sediment transport processes in rivers. For instance, a turbulent flow over a flat sand bed gives rise to a fluctuating shear stress and sediment suspension near the bed that yield the formation of bedforms. Further, the bedforms' shape contributes to flow resistance, the flow structure, and the suspended sediment from the bed.

Recently, a variety of true riverine case studies (Szupiany et al. 2007, Rennie and Church 2010, Guerrero and Lamberti 2011, 2013, Moore et al. 2012, Guerrero et al. 2012, 2013, 2014, Petrie et al. 2013a,b, Williams et al. 2013, Latosinski et al. 2014) has been investigated with the ADCP to non-intrusively characterize the velocity field, suspended sediment patterns, alluvial roughness and bed-load rate; in some cases with resolution and coverage that were previously unavailable by using traditional measurement devices. The potential capability of estimating the three classes of process with an individual acoustic instrument is therefore attractive for the understanding of sediment transport in rivers.

This paper gives a review of the ADCP methods to investigate the three mentioned classes of parameters with a particular focus on: (i) the friction velocity estimation, and (ii) assessment of suspended sediment concentration and grain size. In addition, the ADCPs recording in the Po River in Italy were used to calibrate the shallow water approximation numerical model (code MIKE21C) written by the Danish Hydraulic Institute. The calibrated model was then applied to plan the dredging activities for the maintenance of a pump station intake for irrigation that is periodically obstructed with a sandbar, eventually showing the gain of using innovative techniques to investigate sediment transport in a practical case. 


\section{ADCP METHODS}

\section{Friction velocity estimation}

A well-established fact is that instrumental error and turbulence oscillation strongly affect ADCP velocity profiles (Muste et al. 2004a,b, Szupiany et al. 2007, Guerrero and Lamberti 2011, 2013).

Space-averaging of moving-ADCP data was developed to filter out uncertainty from the individual profile measurements, thereby producing reliable maps of the flow field (Guerrero and Lamberti 2011). This method also requires ADCP profiling in some fixed positions to analyse velocity variability. Indeed, the reliability of the obtained maps primarily depends on the compromise between local accuracy and map resolution. In fact, filtering out data uncertainty related to macro-turbulence oscillations means time-averaging over a time window that depends on the case study, for example, the time window changes from 10 to 100 seconds, an order of magnitude, when passing from the Po River in Italy to the large Parana River in Argentina (Guerrero and Lamberti 2011, 2013, respectively). This time window corresponds to the time periods of velocity variability that can be observed in ADCP profiles from fixed positions. In addition, when the instrument is moving, time-averaging implies spatial filtering of the space variability (i.e. resolution loss). Therefore, to choose the space-averaging window length and the size of the interpolation mesh, the observed time periods of velocity variability must be considered.

Turbulence and instrumental errors are particularly critical for friction velocity assessment. In fact, variance along the vertical (depth-axis) of the semi-logarithmic law, which may be related to friction velocity, is partially hidden by the other sources of variability. Considering that some authors (e.g. Muste et al. 2004b, Szupiany et al. 2007) suggested fitting a semi-logarithmic law over as many fixed-ADCP velocity profiles (DVP) as required to filter out turbulence oscillations, the use of moving-boat measurements would not be compatible with the friction velocity estimation purpose. Indeed, the velocity profile in a fixed position may also be affected by stationary processes such as the acceleration over a dune crest that, locally, may strongly deviate the actual profile from the theoretical shape related to shear velocity and bed roughness. Thus, an alternative approach was aimed to apply a moving-ADCP technique to map the friction velocity. This approach was firstly introduced by Guerrero and Lamberti (2011) and presents the advantage of spatial averaging the stationary processes.

The vertical variance (i.e. variance along depth-axis) of moving-ADCP individual profile was related to the vertical variance of the semi-logarithmic vertical profile of streamwise velocities (LVP), and then the latter variance was used to assess the friction velocity. For very large channel cross-section, the flow approximates to a uniform two-dimensional configuration with almost uniform shear stress across the section and maximal velocity near the water surface, and the following LVP is widely accepted:

$$
\frac{u}{u_{*}}=\frac{1}{k} \log \left(\frac{z}{k_{s}}\right)+8.5
$$

where $u$ and $u *$ are the streamwise and friction velocities, $z$ is the distance along vertical axis, $k$ is the Von Karman constant and $k_{s}$ the roughness height. The variance along $z$ (i.e. vertical variance) of the LVP results, as follows using equation (1) integration:

$$
\frac{1}{h} \int_{0}^{h}(u-U)^{2} d z=\frac{u_{*}^{2}}{k^{2}}
$$

where $h$ is the water depth and $U$ the depth-averaged velocity. Thus, from the square root of equation (2), it follows that friction velocity is proportional to LVP standard deviation (std) through the Von Karman constant:

$$
u_{*}=k \cdot \operatorname{std}(u)
$$

The vertical variance of an individual DVP is the sum of the LVP vertical variance plus some uncertainty related to instrumental error and velocity oscillation due to turbulence; it also follows 
that a corrected variance can be estimated for each individual DVP by subtracting profile uncertainty from the corresponding vertical variance. The so-called error-velocity (EV) profile of ADCP may be applied to estimate this uncertainty. In fact, the EV for each ensemble (corresponding to an individual DVP) is defined as the standard deviation over pings (within the individual DVP collecting time) of vertical velocity estimations, which are assessed by summing beam velocities coming from opposite transducer pairs (i.e. 1-3 and 2-4) and are geometrically scaled in the direction of the velocity magnitude. A strong correlation arises between the EV profile (EVP) and the velocity deviation from the semi-logarithmic profile. This agreement shows both data to depend on turbulence variability, but the velocity deviations of each individual DVP from LVP need an appropriate number of ensembles (i.e. individual DVPs) at fixed positions to be assessed, whereas EVP was available at each individual ensemble. This occurrence makes the vertical variance method (i.e. equation (3) proportionality) suited to friction velocity estimation applying the moving-ADCP technique that can also be used to map the friction velocity.

The presented vertical variance method gives the friction velocity at each ensemble, however, cumulative estimations (i.e. averaged over time) limit the overall uncertainty. To this end, the needed collecting time must be evaluated by assessing the variation with averaging time of the normalized mean over time of the difference between DVP and EVP vertical variances in some fixed positions.

\section{Concentration and grain size of suspended sediment}

The ADCP also provide the echo levels from scattering particles, in logarithmic scale. This data can be applied for the indirect measurement of suspended sediment concentration and grain size. The method is based on the principle of a frequency-dependent variation in the backscatter of particles, as was first tested by Hay and Sheng (1992).

In the river environment, experiments were performed to measure sediment concentrations, together with grain size profiles using a moving vessel equipped with $1200-$ and $600-\mathrm{kHz}$ acoustic ADCPs (Guerrero et al. 2011, 2013).

The mass of suspended sediments per unit volume, i.e. the concentration $M$, is related to the backscattering power as (Thorne and Hanes 2002):

$$
M=\frac{s}{\sigma} \rho_{s} \frac{4}{3} \pi a^{3}
$$

where $a$ is the particle radius (particles are assumed to be spherical), $\rho_{s}$ is the particle density, and the ratio $s / \sigma$ gives the number of particles for unit volume. $s$ is the backscattering power, $\sigma$ is the backscattering power for an average single particle within the measurement volume (namely, scattering size). The scattering size is related to the physical size by the form factor $f$ according to Thorne and Hanes (2002), that is a function of $k$ times $a$ (the acoustical wave number-particle radius product, i.e. $x=k \cdot a$ ). The concentration expressions for the two frequencies yield the relationship to solve for the grain size (equation (5)):

$$
\frac{\sigma_{1}}{\sigma_{2}}=\left(\frac{f_{1}}{f_{2}}\right)^{2}=\frac{s_{1}}{s_{2}}=10^{\frac{S_{1}-S_{2}}{10}}
$$

where the subscripts refer to the applied frequencies. Equation (5), which is not dependent on concentration, gives the current mean grain size of an ensonified volume by the two frequencies. The form factors square ratio (in equation (5)) is a function of the sediment grain size and the applied frequencies through $x$, as reported in Hay and Sheng (1992). An advantage of this method is its ability to estimate the mean grain size in the ensonified volume.

The ADCP-measured echo intensity (in a logarithmic scale) is related to the backscattering power as follows:

$$
S-S_{c}=C+K_{c}\left(E-E_{r}\right)
$$

where $C$ and $K_{c}$, are calibration parameters, $S_{c}$ (namely, the backscattering power correction) includes known terms such as the sound dissipations in water; $\left(E-E_{r}\right)$ is the measured effective 
echo intensity which also accounts for echo intensity corresponding to the ambient noise level, $E_{r}$; and $S$ is the backscattering power (in a logarithmic scale, i.e. capitol $S$ in equation (5)).

The sound dissipation due to the presence of suspended sediment is the sum of two terms: (1) viscous dissipation due to the relative motion between sediment particles and water; and (2) sound scattering by particles. Both terms should be accounted in $S_{c}$. Various formulations can be found in the literature to assess these losses; among others, Hanes (2012) reported a comparison between the two terms as a function of sediment size and applied frequency, showing a negative correlation between scattering and viscous dissipations.

\section{THE PO RIVER CASE STUDY}

The 2-D shallow water approximation numerical model (code MIKE21C) written by the Danish Hydraulic Institute was applied to the Po River, the longest river in Italy (Fig. 1(a)). The average and historical maximum discharges are approximately 1500 and $12000 \mathrm{~m}^{3} / \mathrm{s}$, respectively, and the transport of bed sediment has been estimated to have decreased in the last century from $10 \times 10^{6}$ to $5 \times 10^{6} \mathrm{~m}^{3} /$ year based on the past rate of delta extension and land subsidence data.

The investigated section, shown in Fig. 1(b) in the context of the entire Po basin in northern Italy, is near Boretto, $216 \mathrm{~km}$ from the Adriatic Sea, where the catchment area is $55200 \mathrm{~km}^{2}$.

A field survey was conducted in May 2007, at which time moderate flow conditions were present in the river after two dry years (May 2005-May 2007). Two Teledyne RDI ADCPs working at different frequencies $(600$ and $1200 \mathrm{kHz}$ ) were deployed to map the depth-averaged flow field and characterize the river's suspended sediment. Additional details on the Po River survey can be found in Guerrero and Lamberti (2011).

\section{The numerical model}

The code MIKE21C written by the Danish Hydraulic Institute solves the two-dimensional NavierStokes equations on a curvilinear grid using a finite difference scheme. The semi-logarithmic vertical profiles of velocity and the helical secondary flow are taken into account with integrated parameters in the two-dimensional convective-diffusive equation and with the bed load-streamflow misalignment. These features make the model quasi 3-D, but introduce various parameters that need to be accurately calibrated. The sediment continuity and the convective-diffusive equations are solved in a quasi-steady approach to speed up the long-term morphodynamic simulation. Therefore, the model is particularly suited for long-term and slowly variable morphodynamic simulations, and may be applied to predict hydraulic works or flow-regime-change impact on river channel morphology.

For the case study, the steady-state condition of the 2007 survey was simulated to calibrate the hydraulic module on the basis of the estimated alluvial roughness derived from the friction velocity by means of the ADCPs recording. Also, the reliability of the Engelund and Hansen formula was verified for estimating the total transport of bed sand in the Po River. In addition, the

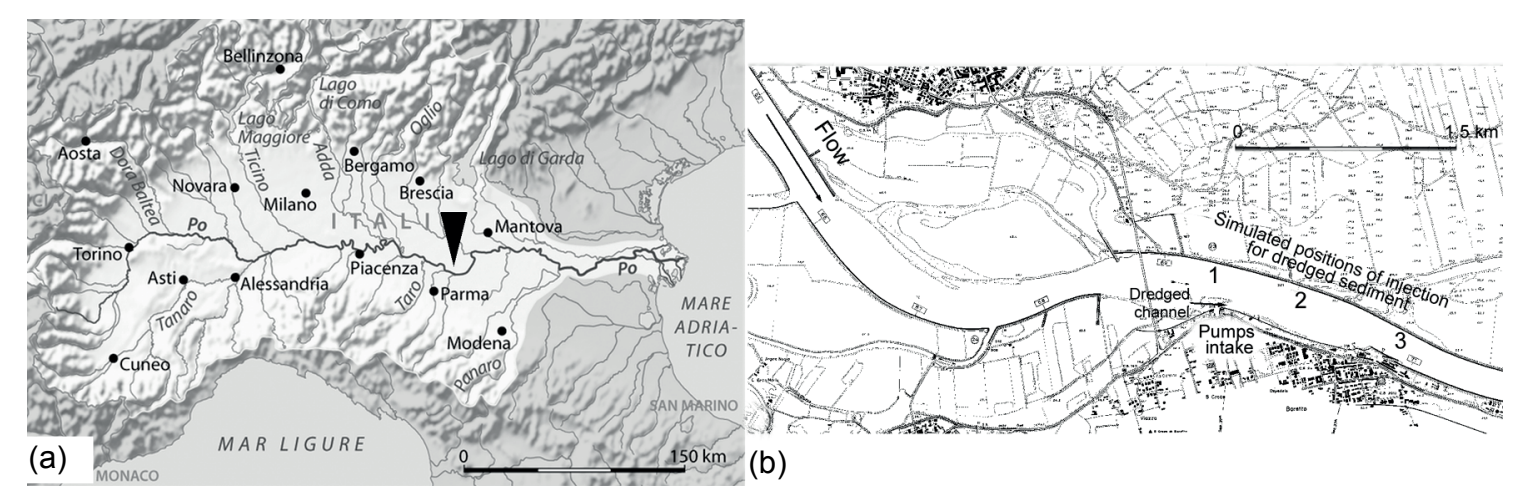

Fig. 1 The Po River watershed (a) and the study reach near Boretto (b) with the pumps intake for irrigation supply. 
sediment transport formulation was validated by comparing the simulated sediment deposition to the recording of dredged volumes to maintain the hydraulic conductivity of the pumps station intake for irrigation purpose in the period May 2005-May 2006. To convey the irrigation discharge towards the pumps intake, the water depth is maintained by dredging $35000 \mathrm{~m}^{3}$ per year along a $700-\mathrm{m}$-long area in the right side of the river channel (Fig. 2).

\section{RESULTS}

The bed roughness of the river channel was inferred from the ADCP profiling of the water velocity during the May 2007 survey. The depth-averaged velocity, friction velocity, and depth maps (Guerrero and Lamberti 2011) were used to assess the distribution of the Chezy parameter, which appeared to be weakly correlated (a correlation coefficient of less than 0.1 ) with the local water depth, and its resulting average value was equal to $46 \mathrm{~m}^{1 / 2} / \mathrm{s}$, corresponding to a Gauckler-Strickler parameter, $k_{s}$, of $36 \mathrm{~m}^{1 / 3} / \mathrm{s}$. These field results are in good agreement with the model results. In fact, the measured and simulated (given $k_{s}$ equal to $36 \mathrm{~m}^{1 / 3} / \mathrm{s}$ ) water slopes were equal to $0.13 \times 10^{-3}$ for the steady-state condition of May 2007 (i.e. $974 \mathrm{~m}^{3} / \mathrm{s}$ ). The simulated distribution of the water depth for $974 \mathrm{~m}^{3} / \mathrm{s}$ follows in the surveyed bed morphology given the best value for $k_{s}$ (i.e. $36 \mathrm{~m}^{1 / 3} / \mathrm{s}$ ).

Regarding suspended sediment, the spatial distributions of depth-averaged concentrations and that of corresponding mean grain size are negative correlated both for simulated and measured values. Although the resulting maps are characterized by variations at different length scales, the observed and modelled distributions substantiated the claim that high concentrations of fine sediment occurred at low-depth areas, corresponding to the locations where sediment deposition formed an alternate bar field during low-flow periods.

In addition, the detailed simulation of sedimentation occurring in the channel dredged to convey water for irrigation during the period of May 2005-May 2006, gave a deposition volume of about $39000 \mathrm{~m}^{3}$ that is in pretty good agreement with the recording of the actual dredged volume for the same period. The simulated total sediment transport also corresponded to an average sediment inflow of $1.4 \times 10^{6} \mathrm{~m}^{3} /$ year that resulted in the lowest deviation between the simulated and surveyed bathymetry, and was fairly close to analytical estimations and historical values from the literature when considering that the simulated period (May 2005-May 2006) was a dry year characterized by a low transport capacity (Guerrero et al. 2013).

\section{A practical application}

The validated model may be applied to the management of dredged sediment. The settling of sediment in the river channel that conveys irrigational discharge to pumps intake was simulated with different positions along the river for the injection of the dredged volume (Fig. 1(b)). Indeed, in the Po River, mining of sediment from the bed is not allowed; however, the sediment is displaced within the river channel to maintain the water way and pumps intake capacity. In the case of pumps intake, the sediment displaced was optimised to limit the sandbar formation obstructing the channel.

The injection of dredged volumes was simulated during May 2005, and in three different positions along the left side of the river channel (Fig. 1(b)). The details of the resulting simulated sediment displace (position 2 in Fig. 1(b)) produced a lower bar protruding towards the pumps intake (Fig. 2(b)), that indicates a larger hydraulic conductivity for irrigation purpose. Indeed, in this case, the injected sediment acts as an artificial groyne that significantly deviates the bathymetries for

(a)

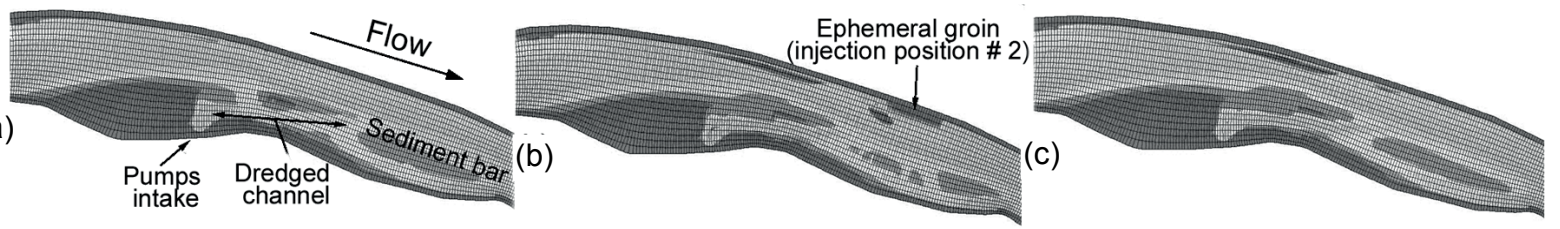

Fig. 2 Simulated depositions at the right side of the river nearby the pumps intake for changing injection position of dredged sediment from upstream (a) to downstream (c), as indicated in Fig. 1(b). 
September 2005, as reported in Fig. 2. The intermediate position for the streamflow is towards the right side of the river channel. Sediment erosion takes place on this side until the ephemeral groyne is completely flushed.

\section{CONCLUSIONS}

The ADCP recordings can be applied for the investigation of sediment processes in rivers, and further laboratory testing and experimental campaigns are needed to characterize the relationships between acoustic properties and sediment transport parameters. In particular, the multi-frequency and error-velocity may also be applied for the investigation of bed-load rate. In fact the error-velocity was related to the friction velocity in field case studies and the Doppler velocity may be applied to estimate the velocity of sediment particles moving over a sandy bed. Given those results and the need of sediment transport data in rivers, the indirect methods using multi-frequency ultrasound should be further tested and improved, eventually developing an ADCP with the capability to accurately estimate suspended-and bed-load to be conveniently applied for the accurate calibration of existing hydro-morphodynamics models.

\section{REFERENCES}

Guerrero, M., Di Federico, V. and Lamberti, A. (2013) Calibration of a 2-D morphodynamic model using water-sediment flux maps derived from an ADCP recording. J. Hydroinformatics 15(3), 813-828.

Guerrero, M. and Lamberti, A. (2011) Flow Field and Morphology Mapping Using ADCP and Multibeam Techniques: Survey in the Po River. J. Hydraul. Engng 137(12), 1576-1587.

Guerrero, M. and Lamberti, A. (2013) Bed-roughness investigation for a 2-D model calibration: the San Martìn case study at Lower Paranà. Int. J. Sediment Res. 28(4), 458-469.

Guerrero, M., Ruther, N. and Archetti, R. (2014) Comparison under controlled conditions between multi-frequency ADCPs and LISST-SL for investigating suspended sand in rivers. Flow Meas. Instr. Doi: 10.1016/j.flowmeasinst.2014.03.007.

Guerrero, M., Ruther, N. and Szupiany, R. (2012) Laboratory validation of ADCP techniques for suspended sediments investigation. Flow Meas. Instr. 23(1), 40-48.

Guerrero, M., Szupiany, R and Amsler M. (2011) Comparison of acoustic backscattering techniques for suspended sediments investigation. Flow Meas. Instr. 22(5), 392-401.

Guerrero, M., Szupiany, R. N. and Latosinski, F. (2013) Multi-frequency acoustics for suspended sediment investigation: validation in the Parana River. J. Hydraul. Res. 51(6), 696-707.

Hanes, D. M. (2012) On the possibility of single-frequency acoustic measurement of sand and clay concentration in uniform suspensions. Cont. Shelf Res. 46, 64-66.

Hay, A. E. and Sheng, J. (1992) Vertical profiles of suspended sand concentration and size from multifrequency acoustic backscatter. J. Geophys. Res. 97 (C10), 15661-15677.

Latosinski, F., et al. (2014) Estimation of Concentration and Load of Suspended Bed Sediment in a Large River by Means of Acoustic Doppler Technology. J. Hydraul. Eng. Doi: 10.1061/(ASCE)HY.1943-7900.0000859

Moore, S. A., et al. (2012) On the application of horizontal ADCPs to suspended sediment transport surveys in rivers. Cont. Shelf Res. 46, 50-63.

Muste, M., Yu, K., and Spasojevic, M. (2004a) Practical aspects of ADCP data use for quantification of mean river flow characteristics. Part I: Moving-vessel measurements. Flow Meas. Instrum. 15(1), 1-16.

Muste, M., et al. (2004b) Practical aspects of ADCP data use for quantification of mean river flow characteristics. Part II: Fixedvessel measurements. Flow Meas. Instrum. 15(1), 17-28.

Petrie, J., et al. (2013a) Data evaluation for acoustic Doppler current profiler measurements obtained at fixed locations in a natural river. Water Resources Research 49(2), 1003-1016.

Petrie, J., et al. (2013b) Combining fixed- and moving-vessel acoustic Doppler current profiler measurements for improved characterization of the mean flow in a natural river. Water Resources Research 49(9), 5600-5614.

Rennie, C. D. and Church, M. (2010) Mapping spatial distributions and uncertainty of water and sediment flux in a in large gravel bed river reach using an acoustic Doppler current profiler. J. Geophys. Res. 115, F03035.

Szupiany, R. N., et al. (2007) Comparison of Fixed and Moving Vessel Flow Measurements with an aDp in a Large River. J. Hydraul. Engng 133(12), 1299-1309.

Thorne, P. D. and Hanes, D. M. (2002) A review of acoustic measurement of small-scale sediment processes. Cont. Shelf Res $22,603-632$.

Williams, R. D., et al. (2013) Hydraulic validation of two-dimensional simulations of braided river flow with spatially continuous aDcp data. Water Resources Research 49(9), 5183-5205. 